\title{
Cancer care professionals should pay more attention to the sexual aspects of cancer in men with a non-mainstream sexual orientation
}

\author{
Woet L Gianotten ${ }^{1 *}$ and Haakon Aars ${ }^{2}$ \\ ${ }^{1}$ Emeritus Senior Lecturer in Medical Sexology, Consultant in Oncosexology, University Medical Centre Utrecht, The Netherlands \\ ${ }^{2}$ Institute for Clinical Sexology and Therapy, Oslo, Norway
}

\begin{abstract}
Cancer and its treatment are known to be associated with much collateral damage in the areas of sexuality and intimacy. Since nature doesn't discriminate, cancer happens also to gay and bisexual men. In men who have sex with men (MSM) cancer treatment can cause serious sexual impairments that are unknown to the average heterosexual health care provider (HCP). Because insufficient appropriate knowledge impairs good cancer care, this article will address relevant aspects of sexual lifestyle, relationships and sexual behavior of MSM and the typical areas where cancer treatment tends to damage.

After prostate cancer treatment there is no more ejaculate, a very important part in the average MSM sexual play. Radical prostatectomy causes climacturia (urine loss during orgasm) in a substantial amount of men. This is a real killjoy for oral sex, which is in MSM the most common way to have sex. Prostate cancer and anorectal cancer treatment damage the possibilities for prostate orgasm, an intense variety of orgasm, common in many MSM. Anorectal cancer treatment can impair the possibilities for various ways of anal sex, especially in the 'bottom man' (the receptive partner). Cancer treatments that impair erection tend to damage more in MSM, not only because erections are in their sexual encounters very relevant for sexual identity, but also because one needs for anal penetration a firmer erection than for vaginal penetration.
\end{abstract}

This review will successively deal with the prevalence of MSM; with relevant aspects of MSM sexuality and MSM lifestyle; with different cancer prevalence in MSM; with consequences of cancer treatment that are typical for the sexuality of MSM; and finally with some aspects of optimal care in MSM with cancer. The aim of the information in this article is both to improve the communication with MSM, and to improve the oncological care for MSM and their partners.

\section{Introduction}

The majority of men is sexually exclusively attracted to women. In a smaller part of men the sexual attraction goes to both men and women or exclusively to men. These men are called MSM (men who have sex with men), a group that includes gay men, bisexual men and men who under another label have sex with men. Traditionally, society and medicine have been strongly influenced by heteronormativity. As a result medical problems of MSM barely got attention, except in the fields of psychiatry, sexual transmitted diseases and HIV. In the more liberal parts of the Western World there is a growing acceptance of nonmainstream sexual orientation. In that changing climate, a small group of HCPs has become aware of the typical challenges for patients with a non-mainstream orientation when they face a chronic disease, aging or cancer [1].

This article will focus on relevant aspects of cancer and cancer care in MSM. The average HCP has been poorly trained to address the needs of MSM, lacking both knowledge and skills [2,3]. To fill those gaps we'll successively address :

- the prevalence of MSM

- aspects of MSM sexuality and MSM lifestyle, relevant for optimal cancer care.

- differences in cancer prevalence between MSM and mainstream men
- consequences of cancer treatment that are typical for the sexuality of MSM

- aspects of optimal care in MSM with cancer

The aim of this article is on the one hand to improve the oncological care for MSM and their partners, and on the other hand also to improve the communication with MSM.

\section{Prevalence of non-mainstream sexual orientation in men}

Most HCPs don't ask questions about sexual orientation and most MSM don't spontaneously disclose that. As a result HCPs tend to underestimate the prevalence of MSM among their patients.

In a representative sample of $>10.000$ Australian men $5.9 \%$ reported some homosexual experience in their lives; $5.0 \%$ reported genital

${ }^{*}$ Correspondence to: Woet L Gianotten, MD, Psychotherapist, Emeritus Senior Lecturer in Medical Sexology, Consultant in Oncosexology, University Medical Centre, Utrecht, The Netherlands, E-mail: woetgia@ziggo.nl

Key words: homosexual men, gay men, bisexual men, MSM, sexual orientation, sexual lifestyle, cancer

Received: August 08, 2018; Accepted: August 25, 2018; Published: August 29, 2018 
sexual experience with a man; and $1.9 \%$ of men reported homosexual experience in the past year [4].

In a recent UK national probability survey on sexual behaviour $>6.200$ men were interviewed [5]. Any sexual experience or contact with another man was indicated by $8.0 \%$ of men. With genital contact included it was reported by $5.5 \%$. At least one male sexual partner in the last 5 years was indicated by $2.6 \%$ of the men.

In a recent USA National Health Interview Survey (NHIS), men were also asked about sexual orientation. Of these nearly 60.000 men $1,8 \%$ was identified as gay and $0,5 \%$ as bisexual [6].

In most research the prevalence of MSM appears higher in the younger generations.

\section{Aspects of MSM sexuality and MSM lifestyle}

There are many similarities between the groups of gay and straight men. Both have a wide variety in sexual behaviour patterns, both are easily visually stimulated, and have a relatively high sexual desire. Both tend to be more focused on the technical than on the emotional aspects of sexuality and, after separation or divorce, both tend to quickly establish a new relationship [7].

There are also relevant differences. With far less pre-paved roads, MSM have to develop their own 'sex rules'. This may make sexuality more of an ordinary topic of conversation in MSM relationships. Sex with multiple partners is among MSM couples more open to discussion and more accepted. There is also more acceptance of sexual contact without commitment. One of the consequences is that MSM tend to invest more in their body and appearance ('looks'), but also in sexual performance.

Within the sexual encounters of MSM, there are also love-making differences that are relevant in the context of cancer treatment. To better understand the common patterns in the sexual life of MSM, we use the data that were collected at EMIS, the 2010 European MSM Internet Survey [8]. Although started to learn more about hiv/aids, this survey created a rich source for information on MSM-sexuality. The age of those men was between 13 and 89 years with a mean of 34.1 years. The survey was answered by $>175.000$ men from all over Europe, which means that part of these men live in rather homo-friendly and others in far more homo-negative countries and surroundings. For describing orientation one tends to use three different components: sexual attraction, sexual identity and sexual behaviour

Sexual attraction: $71 \%$ of respondents reported being sexually attracted to men only, $29 \%$ were attracted to men and women..

Sexual identity: $76 \%$ of the respondents identified themselves as gay or homosexual, $15 \%$ as bisexual and $9 \%$ called themselves 'other'.

Sexual behaviour: in the last 12 months $82 \%$ had only sex with men; $11 \%$ had sex with men and women; $2 \%$ only with women and $5 \%$ reported no sexual contact with anyone.

Outness: Being out or not being out is an important reality in MSM. Outness it is the degree to which people are open about their sexual identity and attraction. Less being out is associated with more unhappiness. Overall, $39 \%$ of the EMIS-respondents were out to all or almost all and $10 \%$ were out to no-one. Anyhow, not-revealing orientation in contact with their HCPs is even in liberal societies very common.

Current partnership status: At the time of the interview $54 \%$ of the respondents were single; $39 \%$ were in a steady relationship with a man;
$6 \%$ in a steady relationship with a woman; and $<1 \%$ had both a male and a female steady partner. Of the men who had a steady relationship with men, $60 \%$ had been in that relationship for over three years. In this European survey, the most common reason for sexual unhappiness was 'wanting but not having a regular sexual partner'.

Actual sexual actions: Contrary to what many people think, anal intercourse is not the most frequent activity. It follows in frequency after oral sex as number one and mutual masturbation as number two (Table 1).

In MSM love-making much value is given to the quality of erection. Over the last four weeks $8 \%$ of the EMIS respondents had used a PDE5inhibitor ('erection pill').

Much value is also given to ejaculation. Besides pleasure and ' $a$ proof of maleness', ejaculation is for most MSM an important part of the sexual play. The sensory experience of viewing and handling the semen is strongly eroticised.

Anal sex includes several aspects, including the high sensitivity of the anal area, the possibility to penetrate or be penetrated and the entrance to the prostate, which represents both an additional erogenous zone and an organ with a different, intense orgasm experience. Stimulating the prostate via the rectal wall creates feelings that are usually experienced more pleasurable than those obtained from penile stimulation [9]. In penetrative anal sex the receptive man is 'the bottom' and the one who penetrates is 'the top'. Approximately a quarter of MSM is always top, a third always bottom and the rest 'versatile' [10]. Sexual positioning is a relevant line of research in relation to aspects like partner role, identity, and STI-risks [10]. However, in cancer care we look at the consequences of treatment. An intact anus and a prostate without pain are relevant for 'the bottom man'. A rigid erection is an essential need for the 'top man' to penetrate the tight anal sphincter. Compared with vaginal penetration, more axial rigidity is required for anal penetration.

Actual sexual experiences in the last 12 months: Sex with one or more steady male partners was indicated by $58 \%$ of the respondents and $10 \%$ of them never had anal sex with the steady partner.

Sex with one or more non-steady partners was indicated by $67 \%$. That involved in $11 \%$ one partner; in $40 \%$ 2-5 partners; in 19\% 6-10 partners and in $30 \% \geq 11$ non-steady partners in the last year.

For these $67 \%$ who had sex with a non-steady partner (i.e. $>117.000$ men) Table 1 shows the percentages of various sexual activities that had taken place over the last 12 months, activities that are relevant in the context of cancer treatment [8] (Table 1).

After having explained all that variety, it will be clear that, without asking, the HCP cannot know the specific sexual behaviour of his MSM patient. Inquiring about relevant details of a man's sexual behaviour isn't a sign of inappropriate curiosity, but of respectful attention.

Table 1. Sexual activities with non-steady partners relevant in the context of cancer treatment

\begin{tabular}{|l|l|}
\hline Sexual activities & EMIS 2010 \\
\hline Passive fellatio (have penis sucked) & $96,6 \%$ \\
\hline Active fellatio (suck a man's penis) & $96,2 \%$ \\
\hline Mutual masturbation & $89,8 \%$ \\
\hline Passively the anus being licked & $76,0 \%$ \\
\hline 'Active' anal intercourse (penetrating) & $74,4 \%$ \\
\hline 'Passive' anal intercourse (being penetrated) & $72,5 \%$ \\
\hline Being fist-fucked (with hand in the rectum) & $10,5 \%$ \\
\hline NB No anal sex with non-steady partner & $17,0 \%$ \\
\hline
\end{tabular}




\section{Differences in cancer prevalence between MSM and mainstream men}

Although cancer incidence is supposed not to be influenced by orientation itself, recent USA data showed that above age 65 the probability of a cancer diagnosis in gay men is $6 \%$ higher than in heterosexual and bisexual men [6].

In California research the prevalence of cancer in gay men was almost double that of mainstream and bisexual men [11]. Whereas the prevalence of colon cancer and melanoma was not higher in gay men, the prevalence of other cancers was higher, but striking was the much lower prevalence of prostate cancer among gay men (at about one-third of the prevalence in other men).

An Australian all-men case-control study on prostate cancer found that men who had never been married had an odds ratio (OR) of 0.56 and that MSM had an OR of 0.66 (although this was based on few men) [12].

We guess that this lower risk to contract prostate cancer should not be explained by 'being gay', but by the higher ejaculation frequency of MSM throughout adult life. A large US-based study showed that more frequent ejaculation has a beneficial role in the etiology of prostate cancer, particularly for low-risk disease [13].

Several explanations are given for higher rates of other cancers in MSM [6].

- Minorities report worse health outcomes due to more 'minority stress' and more unhealthy behaviour. In the last NHIS, a higher percentage of MSM reported smoking and alcohol use. The other side was that the MSM group has a more healthy weight [6].

- MSM appear to experience more barriers to routine medical care and routine cancer screening. Whereas MSM more frequently underwent colorectal cancer screening, they had less prostate cancer screening [6].

- MSM run higher risks for cancer because of the consequences of some of the MSM-lifestyle elements. Factors like less monogamy and more freedom to act on sexual adventurism result in a far higher incidence of sexual transmitted infections (STI) including HIV, that finally directly can cause cancer or indirectly attribute to its development $[14,15]$.

Especially unprotected anal sex is a major route of pathogen transmission because of the combination of extensive anal blood circulation and microtraumata (with a higher risk of becoming infected in receptive sex than in insertive sex).

The relevant pathogens for oncology are HBV, HCV, HHV-8 and several HPV-viruses. Added to that is HIV as a risk factor for the development of various cancers.

HPV (human papilloma virus): HPV infection is associated with $80-90 \%$ of anal cancers, and a high proportion of oropharyngeal (included tonsillar) and penile cancers. Anal HPV infections are very common in men who have sex with men (MSM), and nearly universal among HIV-infected MSM.

Whereas oral HPV is rare in the general population, it appears to be common in MSM, one of HPV's high-risk groups. In particular HPV16 infection increases the risk of oropharyngeal cancer.

HBV (hepatitis B virus). Whereas a HBV infection is self-limiting in the majority of patients, others develop a chronic hepatitis, that finally can progress into liver cancer and that is also associated with increased risk of non-Hodgkin's lymphoma (NHL) [14].

HCV (hepatitis C virus): Sexual transmission of HCV actually only occurs in MSM who are HIV positive. Most individuals with hepatitis C will develop a chronic hepatitis, that finally can develop into liver cancer and that is also associated with an increased incidence of NHL [14].

HHV-8 (human herpesvirus type 8, also called KSHV (Kaposi's sarcoma associated herpes virus) is found more in MSM than in mainstream men [15]. The virus is transmitted through saliva and replicates in oropharyngeal cells. It is the causative agent of Kaposi's sarcoma, but apparently also in some other lymphoproliferative diseases [16]. Kaposi's sarcoma is the most common neoplasm in untreated HIV-infected people.

HIV (human immunodeficiency virus): In the Western World a substantial amount of carriers are known and treated. For the year 2010 UNAIDS reported that in Europe 6.1-6.6\% of MSM were HIV-positive, in Northern America $15.4 \%$ and in the Carribean 25.4\% [17]. Being HIV-positive is an additional risk factor for the development of some cancers, especially the virus associated cancers, but also some non-virus associated cancers [14]. Table 2 shows, according to Gopal, the relative risk to develop cancer when HIV positive, compared to the general male population, with indication of the known oncogenic viruses) [14].

In resource-rich settings cancer has become a leading cause of HIVassociated death [14].

\section{Different consequences of cancer treatment in MSM}

Up till now very few articles have been dealing with the specific sexual consequences of cancer treatment in MSM. On the one hand there are the more general consequences, based on the fact that MSM put more value on appearance and sexual performance. Collateral sexual damage to those values will hit more than average in the subgroup of MSM for whom a substantial part of sexual encounters was found in casual contacts; and also in the subgroup of single MSM who are still looking for a steady partner.

On the other hand there is the damage when a treatment for a specific cancer interrupts the MSM sexual life-style or sexual possibilities.

Attributing relatively more value to sexuality gives MSM also some benefits in dealing with cancer. They will more easily follow the recommendations of a sexual rehabilitation program [18].

We'll address the most important recognised sexual consequences of various cancers.

\section{Anal cancer and rectal cancer}

Extensive anal surgery will impair or completely stop the opportunity for various receptive anal activities. Radiotherapy in the

Table 2. Relative risk to develop cancer when HIV positive

\begin{tabular}{|l|c|c|}
\hline \multicolumn{1}{|c|}{ Cancer type } & Relative risk & Known oncogenic virus \\
\hline Kaposi's sarcoma & $100-1.000$ & KSHV (=HHV-8) \\
\hline Burkitt's lymphoma & $20-100$ & EBV / KSHV \\
\hline anal cancer & $10-100$ & $\mathrm{HPV}$ \\
\hline non-Hodgkin's lymphoma & $5-50$ & $\mathrm{EBV} / \mathrm{KSHV}$ \\
\hline Hodgkin lymphoma & $5-20$ & $\mathrm{EBV} / \mathrm{KSHV}$ \\
\hline liver cancer & $3-10$ & $\mathrm{HBV}, \mathrm{HCV}$ \\
\hline lung cancer & $2-4$ & none \\
\hline melanoma & $2-3$ & none \\
\hline head-neck cancer & $1,5-3$ & $\mathrm{HPV}$ \\
\hline
\end{tabular}


anal area damages the elasticity of the anal muscles and the regenerative capacity of the mucous membrane. Then receptive anal intercourse can become temporarily or permanently painful or even impossible. After radiotherapy, some of the men complain that the anal mucosa and skin have become painfully sensitive. That happens also after most treatments for high-grade anal intraepithelial neoplasia. This precursor of anal cancer is present in about 30\% of the HIV-positive MSM [19]. As a consequence of this sexual side effect some men apparently abstain from further treatment (and so increase the risk to progression into full anal cancer).

\section{Colorectal cancer}

The lower the cancer is situated in the colon, the greater the risk for erectile problems. Erectile disturbance will damage the 'top man' relatively more. A temporary or permanent colostomy will create for many MSM a handicap in the sexual encounters with a stable partner. In usually causes serious impairment in finding a new steady partner or non-steady partners.

\section{Prostate cancer}

Gradually research on MSM after prostate cancer treatment is on the go. Compared to mainstream men, MSM appear to suffer more in the mental domain and the physical domain, but less in some aspects of the sexual domain [20]. In another survey comparing MSM and mainstream men after prostate cancer treatment, the major outcome difference was for MSM the far bigger importance of lost ejaculation [21]. In Australian comparative research MSM reported lower health related quality of life, lower masculine self-esteem, lower satisfaction with treatment, higher psychological distress, higher cancer related distress and more ejaculatory concern, but they also reported higher sexual functioning and higher sexual confidence [22].

We'll address the consequences of the various treatment modalities.

\section{Prostate cancer; surgical approach}

Radical prostatectomy will nearly always impair the erectile capacity (which in anal sex is relatively more damaging to the 'top man').

Several aspects of sexual play that are far more common in MSM are lost. There will be no more prostate massage and no more prostateinduced orgasms. There will also be no more ejaculation and no more semen, which for many men means an 'incomplete sexual encounter'.

The urinary incontinence after radical prostatectomy is disturbing, but will disappear in $98 \%$. However, about $30 \%$ of men (20-93\%) will for a while keep climacturia (urinary incontinence at orgasm) [24]. That's a real kill-joy in nearly all couples (MSM and heterosexual.) who love oral sex up to oral orgasm. It appears that some MSM enjoy the climacturia.

Although usually not mentioned (because it is not asked), there are several other forms of sexual collateral damage of radical prostatectomy: no orgasm (5-40\%); delayed orgasm (60\%); altered orgasm perception (70-80\%); orgasmic pain (3-20\%); penile shortening (37\%); and altered penile sensation (25\%) [23-25]. Those are all sexual troubles that will hit hard in MSM.

\section{Prostate cancer; radiotherapy approach}

Both external beam radiation and brachytherapy cause a high percentage of erectile dysfunction, that gradually will develop over a period of 2-3 years. The pleasurable sensations of prostate massage and prostate orgasm will disappear. There will be no more ejaculation.
The prostate itself can be painful and also what is left of orgasm. Between $5-15 \%$ of the men develop a radiation proctitis with longlasting diarrhea, which is especially damaging to the love-life of the 'bottom man' and his partner.

In the bottom man who undergoes brachytherapy, the radioactive seeds are dangerous for the penis of the inserting partner for a period of 2-6 months (depending of which seeds have been used) [26].

\section{Prostate cancer; ADT (Androgen Deprivation Treat- ment)}

Without testosterone the production of seed will stop. The majority of men will lose sexual desire and arousal and some $80 \%$ will lose their erections. ADT also causes major changes in male appearance and male identity with different degrees of gynecomastia, female fat distribution, hot flashes, bouts of crying, tiredness and lowered assertiveness. In straight men such damage to male sexual identity appears to be far greater in the more masculine types. In MSM the sexual positioning roles (top or bottom) are partly also seen as representing varying degrees of masculinity [10] It is tempting to assume that some bottom men will deal better than average with part of these demasculinizing ADT-effects.

\section{Head \& neck cancer}

With oral HPV being common in MSM, they have become one of HPV's high-risk groups. Treatment of this cancer can disturb appearance, saliva production, verbal communication and other oral skills. With their high value on appearance and oral sex, MSM tend to suffer more than mainstream men. Especially when local radiotherapy has destroyed saliva production and the oral sensations have gone [27].

\section{Blood/lymph cancer}

MSM who carry HBV, HCV or HIV have an increased risk to contract Hodgkin lymphoma and NHL [14]. The survival of MSM with NHL appears shorter than for mainstream men [28].

Both chemotherapy and total body irradiation can bring down the testosterone levels, causing low desire and arousability. By impairing immunity these treatments can also reactivate former viral infections (with painful and distracting oral herpes, genital herpes or anal condylomata), a common reality in the medical history of many MSM.

\section{Different aspects of dealing with cancer in MSM}

MSM and mainstream men who get cancer and cancer treatment share many similar challenges. MSM have in addition extra challenges that are related to the burden of a less accepted minority and to different sexual practices. Gay and heterosexual couples who are confronted with male cancer share also many similar challenges, but they have also key differences. Gay couples were for instance found to have particular sexual roles and can engage in novel accommodation practices, such as open relationships, not seen in heterosexual couples with cancer [29].

We'll give some 'good practice' recommendations to implement all above mentioned information in good oncological care.

\section{1) Do not naturally expect heterosexuality}

It is obvious that the sexual orientation of a patient cannot be taken for granted. After asking the man if he has a relationship, we recommend to immediately continue with the question if that is with a male or a female partner (or with both or with more than one). This appears a relevant step against the patient's fear for the 
HCP's heteronormativity or homophobia. Besides, acknowledging sexual orientation is a good way to facilitate the communication [3].

2) When there is a partner, involve him (or them) just as in straight couples

Whereas in cancer care partners are always important, that is even more so in MSM couples. Frequently they are the most relevant support. For managing home, for caretaking and for support in decision-making. That applies also to the palliative stage. The remaining partner of an MSM couple deserves our care and attention as well. It can be very relevant to know the legal status of the gaycouple. It is not uncommon that the family pushes the partner(s) aside in this phase of the treatment [30].

3) Be aware of potential (orientation-related) psychological disturbances

For some men who didn't deal well with their homosexuality, the cancer diagnosis can (re-)create much guilt and shame? Especially in a strong religious surrounding, the cancer can be felt as a punishment for sexual sins or hidden lifestyle and be accompanied by depression, suicide (or attempts) and PTSS. Some MSM react with refusing. Some men prefer to die from the cancer, rather than to disclose to peers and family about their HIV-status and their homosexual encounters.

4) Be more than average, aware of the importance to pay attention to sexuality and intimacy

Independent of sexual orientation, nearly no patient will spontaneously address sexuality. They want the HCP to start that discussion. After the topic of sexuality and intimacy have been opened up (and after the sexual orientation has come in the open), the HCP can proceed, depending on his or her sexological knowledge and expertise. Then, for several reasons the communication with MSM can be 'easier.' On the one hand MSM can deal well with explicit sexual talk. On the other hand most MSM will understand that the HCP with a mainstream orientation will lack relevant MSMknowledge. They will eagerly answer questions and explain when they feel that the HCP is really interested to help and offer good cancer care. Different are also the genuine efforts of MSM to make the best of the remaining sexual possibilities. They will more easily follow the recommendations of a sexual rehabilitation program [18].

That attitude will also facilitate the process of referring to a sexology expert or sexual medicine expert, when HCP and MSM both are convinced that the man or couple deserves optimal care.

5) Integrate sexuality and preferred sexual scripts in the (shared) decision making

Aspects of sexuality tend to be forgotten as relevant arguments in the process of shared decision making. Especially in prostate cancer and colorectal cancer, aspects of the patient's sexual scripts (like prostate massage; and being usually top or usually bottom) are relevant when a treatment strategy has to be decided. Proper knowledge and information are a prerequisite for proper, fine-tuned cancer care. One preferred approach is by explicitly asking about the sexual scripts of the man or the couple, and from there explain the sexual advantages and disadvantages of the different treatment strategies. If the HCP finds that (still) too scary, one can approach this also more implicitly: 'In case you prefer the top position, then this treatment approach will . . .! Et cetera.' Such discussion should include maximum integration of the partner.

\section{6) Take care that sexual disturbances are properly addressed}

This can be done either by treating the disturbances oneself or by referring properly (depending on the expertise the HCP has developed in the areas of sexual medicine or oncosexology) [31,32].

Hereunder we'll indicate some practical recommendations, more or less typical for MSM patients.

- Don't forget the importance of external appearance, relevant for male identity, but also relevant to be desired by the steady partner or by one-night stands. Proactively consider reconstructive or esthetic surgery and physiotherapy.

- Regarding erectile dysfunction. Proactively explain and offer the full range of erectile enhancing possibilities. In case of prostate and colorectal cancer, invest in sexual rehabilitation [18].

- Regarding the consequences of oropharyngeal cancer. Loss of attractiveness is important. Don't forget to pay attention to mourning. Be aware of the great importance of oral sex. Proactively address loss of saliva and how that could be tackled [27].

- Regarding climacturia (losing urine during orgasm) after radical prostatectomy. The most simple solution is an elastic constriction band round the base of the penis, tight enough to close the urethra (with the additional benefit of enhancing the erection).

- Regarding loss of ejaculation. Don't forget the relevance of mourning and wherever needed, try to assist in renegotiating intimacy.

- Regarding blood-lymph cancer and other situations with extensive chemotherapy or total body irradiation that can have brought down the testosterone level. Proactively inquire about sexual desire and when needed consider testosterone substitution.

On a meta-level optimal care for the sexuality of MSM with cancer could be approached with the common triad of knowledge, attitude and skill.

Knowledge is what we have tried to offer in this article.

Attitude is less easy to grasp. Although HCPs are supposed to treat each patient with respect and dignity, doing so can be difficult when one is brought up in a society where heterosexism is the norm and where non-mainstream orientation is frowned upon or outright discriminated.

In the more liberal parts of the more liberal societies a mutual exchange on orientation aspects gradually took place between HCPs and MSM. By coming out in the medical consultation MSM assisted their HCPs to understand and learn about proper care. On the other hand, the more HCPs inquired about orientation, the easier MSM could come out, so that they together could develop the best care.

And skills? Skills can only be developed by actually doing. Just inquire, just be curious! After all, MSM are not dangerous and they are nearly always happy to help you understand!

What does that yield?

Sexual quality of life is a strong predictor and one of the core elements in general quality of life. So properly dealing with that area will give overall improvement.

In addition, integrating orientation and aspects of sexual lifestyle in the contact between $\mathrm{HCP}$ and patient will give a more constructive 
communication on other aspects of oncological care, included more compliance.

\section{References}

1. Højgaard AD, Aars H (2017) Homosexual men and women, cancer and the health care system. In: Reisman Y, Gianotten WL. (Eds.) Cancer, Intimacy and Sexuality; a practical approach. Springer: 267-277.

2. Lisy K, Peters MDJ, Schofield P, Jefford M (2018) Experiences and unmet needs of lesbian, gay, and bisexual people with cancer care: A systematic review and metasynthesis. Psychooncology 27: 1480-1489. [Crossref]

3. Rose D, Ussher JM, Perz J (2017) Let's talk about gay sex: gay and bisexual men's sexual communication with healthcare professionals after prostate cancer. Eur J Cancer Care (Engl) 26: e12469. [Crossref]

4. Grulich AE, de Visser RO, Smith AM, Rissel CE, Richters J (2003) Sex in Australia: homosexual experience and recent homosexual encounters. Aust $N$ Z J Public Health 27: 155-163. [Crossref]

5. Mercer CH, Tanton C, Prah P, Erens B, Sonnenberg P, et al. (2013) Changes in sexual attitudes and lifestyles in Britain through the life course and over time: findings from the National Surveys of Sexual Attitudes and Lifestyles (Natsal). Lancet 382: 17811794. [Crossref]

6. Gonzales G, Zinone R (2018) Cancer diagnoses among lesbian, gay, and bisexual adults: results from the 2013-2016 National Health Interview Survey. Cancer Causes Control 29: 845-854. [Crossref]

7. Aars H (2011) Menns seksualitet ('Male Sexuality') Cappelen Damm. Oslo.

8. The EMIS Network (2013) EMIS 2010: The European Men-Who-Have-Sex-With-Men Internet Survey. Findings from 38 countries. Stockholm: European Centre for Disease Prevention and Control, 2013. [http://www.emis-project.eu/final-report]

9. Levin RJ (2018) Prostate-induced orgasms: A concise review illustrated with a highly relevant case study. Clin Anat 31: 81-85. [Crossref]

10. Dangerfield DT 2nd, Smith LR, Williams J, Unger J, Bluthenthal R (2017) Sexua Positioning Among Men Who Have Sex With Men: A Narrative Review. Arch Sex Behav 46: 869-884. [Crossref]

11. Boehmer U, Miao X, Ozonoff A (2011) Cancer survivorship and sexual orientation. Cancer 117: 3796-3804. [Crossref]

12. Giles GG, Severi G, English DR, et al. (2003) Sexual factors and prostate cancer. BJU Int 92: 211-216. [Crossref]

13. Rider JR, Wilson KM, Sinnott JA, Kelly RS, Mucci LA, et al. (2016) Ejaculation Frequency and Risk of Prostate Cancer: Updated Results with an Additional Decade of Follow-up. Eur Urol 70: 974-982. [Crossref]

14. Gopal S, Achenbach CJ, Yanik EL, Dittmer DP, Eron JJ, et al. (2014) Moving forward in HIV-associated cancer. J Clin Oncol 32: 876-880. [Crossref]

15. Boehmer U, Cooley TP, Clark MA (2012) Cancer and men who have sex with men: a systematic review. Lancet Oncol 13: e545-553. [Crossref]

16. Mesri EA, Cesarman E, Boshoff C (2010) Kaposi's sarcoma and its associated herpesvirus. Nat Rev Cancer 10: 707-719. [Crossref]
17. Beyrer C, Baral SD, van Griensven F, Goodreau SM, Chariyalertsak S, et al. (2012) Global epidemiology of HIV infection in men who have sex with men. Lancet 380 367-377. [Crossref]

18. Kirby MG, White ID, Butcher J, Challacombe B, Coe J, et al. (2014) Development of UK recommendations on treatment for post-surgical erectile dysfunction. Int $J$ Clin Pract 68: 590-608. [Crossref]

19. Schim van der Loeff MF, Mooij SH, Richel O, de Vries HJ, Prins JM (2014) HPV and anal cancer in HIV-infected individuals: a review. Curr HIV/AIDS Rep 11: 250-262. [Crossref]

20. Hart TL, Coon DW, Kowalkowski MA, Zhang K, Hersom JI, et al. (2014) Changes in Sexual roles and Quality of Life for Gay Men after Prostate Cancer: Challenges for Sexual Health Providers. J Sex Med 11: 2308-17. [Crossref]

21. Wassersug RJ, Lyons A, Duncan D, Dowsett GW, Pitts M (2013) Diagnostic and outcome differences between heterosexual and nonheterosexual men treated for prostate cancer. Urology 82: 565-571. [Crossref]

22. Ussher JM, Perz J, Kellett A, Chambers S, Latini D, et al. (2016) Health-Related Quality of Life, Psychological Distress, and Sexual Changes Following Prostate Cancer: A Comparison of Gay and Bisexual Men with Heterosexual Men. J Sex Med 13: 425-434. [Crossref]

23. Vendeira PM, Fode M (2018) Contemporary management of post-prostatectomy sexual dysfunction. From penile rehabilitation towards a global sexual assessment. Workshop held at the World Meeting on Sexual Medicine. Lisbon 03-03-2018.

24. Clavel-Hernández J, Martin C, Wang R (2018) Orgasmic dysfunction following radical prostatectomy.: Review of Current Literature. Sex Med Rev 6: 124-134. [Crossref]

25. Ussher JM, Perz J, Rose D, Dowsett GW, Chambers S, et al. (2017) Threat of Sexua Disqualification: The Consequences of Erectile Dysfunction and Other Sexual Changes for Gay and Bisexual Men With Prostate Cancer. Arch Sex Behav 46: 2043-2057. [Crossref]

26. Nasser NJ, Cohen GN, Dauer LT, Zelefsky MJ (2016) Radiation safety of receptive anal intercourse with prostate cancer patients treated with low-dose-rate brachytherapy. Brachytherapy 15: 420-25. [Crossref]

27. Jones K (2017) Sexual consequences of head and neck cancer. In: Reisman Y, Gianotten WL (eds). Cancer, Intimacy and Sexuality; A practical approach. Springer: 175-178.

28. Holly EA, Gautam M, Bracci PM (2002) Comparison of interviewed and noninterviewed non-Hodgkin's lymphoma (NHL) patients in the San Francisco Bay Area Ann Epidemiol 12: 419-425. [Crossref]

29. Hartman ME, Irvine J, Currie KL, Ritvo P, Trachtenberg L, et al. (2014) Exploring gay couples' experience with sexual dysfunction after radical prostatectomy: a qualitative study. J Sex Marital Ther 40: 233-253. [Crossref]

30. Stein GL, Almack K (2012) Care near the end of life. In: Ward R, Rivers I, Sutherland M. Lesbian, gay and transsexual ageing. London, Jessica Kingsley Publishers: 1141131. [Crossref]

31. Mulhall JP, Incrocci L, Goldstein I, Rosen R (Eds). (2011) Cancer and Sexual Health. New York, Humana Press.

32. Reisman Y, Gianotten WL (Eds). (2017) Cancer, Intimacy and Sexuality; A practical approach. Springer.

Copyright: $\ 2018$ Gianotten WL. This is an open-access article distributed under the terms of the Creative Commons Attribution License, which permits unrestricted use, distribution, and reproduction in any medium, provided the original author and source are credited. 